\title{
Pseudotumour of the temporal bone: an unusual cause of otorrhoea and facial palsy
}

\author{
Chris Coulson · Ajith George • A. Biswas •
}

C. Phelan · Ranit De

Published online: 8 December 2007

(C) Springer-Verlag 2007

Erratum to: Eur Arch Otorhinolaryngol

DOI 10.1007/s00405-007-0500-0

The title of the article should read:

Pseudotumour of the temporal bone: an unusual cause of otorrhoea and facial palsy

The online version of original article can be found under doi: 10.1007/s00405-007-0500-0.

C. Coulson · A. George · R. De Department of Otolaryngology,

University Hospital of North Staffordshire, Stoke-on-Trent, UK

A. Biswas $\cdot$ C. Phelan

Department of Histopathology,

University Hospital of North Staffordshire, Stoke-on-Trent, UK

C. Coulson $(\square)$

ENT Department, University Hospital of North Staffordshire,

Stoke-on-Trent, UK

e-mail: chriscoulson@doctors.org.uk 